\section{No. 4003 July 20, 1946}

It is hoped to complete detailed investigations on the spread and Ifect of the disease and on the nature of the vector in the course of the present growing season.

Department of Botany,

University College,

Exeter.
June 19.

1 Caldwell, J., Ann. App. Biol., 21, 191 (1934).

\section{JOHN W. BLENCOWE} JOHN CALDWELL

\title{
Effect of Copper-Enzyme Poisons on Soil Nitrification
}

THE possible biological importance of an activated copper nitrogen complex has been repeatedly stressed by Baudisch ${ }^{1}$. I have therefore tried the effect of some well-known copper-enzyme poisons on soil nitriflcation, which is the process whereby ammonium ions are oxidized to nitrite ions and thence to nitrate ions by the microflora in soil The percolation apparatus used in this work was an improved and simplifled version ${ }^{2}$ of the one already described ${ }^{3}$.

Ten grams of a Kent marsh soil were initially percolated with $100 \mathrm{ml}$ of $M / 200$ ammonium chloride to stimulate nitrifying activity in the soil. When the soil was nitrifying well (as indicated by a rapid rise of nitrate in the percolate) the percolate was discarded and the rise of nitrate in the percolate) the percolate was discarded and the soll rinsed three times with $50 \mathrm{ml}$. lots of a $M / 250$ solution of one of the poisons. After the poison had been in contact with the soil for two and the soil repercolated overnight either with $100 \mathrm{ml}$. distilled water and with $100 \mathrm{ml}$, of a $M / 1,000$ solution of cupric, ferrous or manganous or with $100 \mathrm{ml}$. of a $M / 1,000$ solution of cupric, ferrous or manganous sulphate. The next morning this new percolate was again discarded nitrogen plus nitrogen plus nitrate-nitrogen concentration in the percolate was of nitrite-nitrogen plus nitrate-nitrogen formed per gram of soil calculated from the results.

The results from a number of different experiments show that al the four poisons tried reduced the rate of nitrification in soil. There is furthermore evidence that cupric, and perhaps ferrous, ions are capable of partially reversing the poisoning effect.

MICROGRAMS OF NITRITE PLUS NITRATE-NITROGEN FORMED IN TWO DAYS PER GRAM OF KENT MARSH SOIL

\begin{tabular}{|c|c|c|c|c|}
\hline Poisoned with & \multicolumn{4}{|c|}{$\begin{array}{l}\text { Perfused overnight with } \\
\text { Water } \mathrm{CuSO}_{4} \quad \mathrm{FeSO}_{4} \quad \mathrm{MnSO}_{4}\end{array}$} \\
\hline $\begin{array}{l}M / 250 \text { potassium ethyl xanthate } \\
M / 250 \text { sodium diethyl dithio- }\end{array}$ & tr. & 120 & 50 & 70 \\
\hline carbamate & 20 & 220 & 50 & 20 \\
\hline$M / 250$ salicylaldoxime & 10 & 180 & 120 & 0 \\
\hline$M / 250$ allylthiourea & 50 & 50 & 50 & 50 \\
\hline Unpoisoned control & 400 & * & 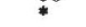 & 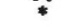 \\
\hline
\end{tabular}

* A separate set of control experiments showed that the metal solutions themselves had no effect on the nitrification rate.

Experiments in which the oxidation of nitrite to nitrate by soil was studied separately gave results that showed a similar action of copper poisons on this process. The effect here was not, however, quite so strong.

The results suggest that copper and/or some allied elements play an important part in the oxidation of ammonium ions in soil by the soil microflora. Preliminary results obtained by Drs. Mann and Heintze in this laboratory show that the rate of oxidation of manganous ions may also be reduced by these same copper-enzyme poisons. Reactivation is, however, difflcult here because of the toxic action of quite dilute copper solutions on manganese oxidation.

\section{Rothamsted Experimental Station,}

HOWARD IEES

Harpenden

June 12 .

1 See, for example, Baudisch, 0., Soil Science, 60, 173 (1945).

${ }^{2}$ Lees, H., in the press.

\section{Anti-Oxygen Stabilization of Bilirubin in Alkaline Medium by Ascorbic Acid and Cysteine}

WE have shown in earlier publications ${ }^{1,2}$ that ascorbic acid and cysteine prevent the oxidation of bilirubin in alkaline medium. The cysteine prevent the oxidation of bilirubin in alkaline medium. The
effect of both substances was ascribed hypothetically to their antieffect of both substances was ascribed hypothetically to their anti-
oxygen properties. The mechanism of action of the anti-oxygen oxygen properties. 'The mechanism of action of the anti-oxygen agents had not been elucidated. On the other hand, the protective action of ascorbie acid and cysteine for bilirubin might equally be oxidized bilirubin to be promptly reduced in alkaline solution, when vitamin $\mathbf{C}$ or cysteine is added.

This hypothesis has been verifled as follows: $10 \mathrm{mgm}$. bilirubin Hoffmann-La Roche, identical with Fischer's product, are dissolved in 500 c.c. $N / 50$ sodium hydroxide. The oxidation of the pigment, which begins almost immediately, is characterized photometrically, as in previous experiments in collaboration with A. Lambrechts ${ }^{3}$, by a continuous decrease of absorption in the region of $4300 \mathrm{~A} .24$ hours later, while the initial extinction coefficient at $4300 \mathrm{~A}$. is 1.84 the contrary, shows a considerable decrease in its absorption, its

extinction coefficient being $0 \cdot 22$. To two 100 c.c. samples of this oxidized bilirubin solution, we then add respectively $40 \mathrm{mgm}$. ascorbic acid and $94 \mathrm{mgm}$. cysteine hydrochloride neutralized by 10 per cent sodium hydroxide. These solutions are immediately examined by means of the Pulfrich photometer, and again after 3 and 6 hours. The accompanying table shows the photometric values recorded.

\begin{tabular}{|c|c|c|c|c|c|c|}
\hline \multirow{2}{*}{ S. } & \multicolumn{3}{|c|}{$\begin{array}{l}\text { Oxidized bilirubin } \\
\text { ascorbic acid }\end{array}$} & \multicolumn{3}{|c|}{$\underset{\text { cysteine }}{\text { Oxidized bilirubin }}+$} \\
\hline & $K$ immed. & $\begin{array}{c}K \text { after } \\
3 \text { hr. }\end{array}$ & $\begin{array}{c}K \text { after } \\
6 \mathrm{hr} .\end{array}$ & $\boldsymbol{K}$ immed. & $\begin{array}{c}K \text { after } \\
3 \mathrm{hr} .\end{array}$ & $\begin{array}{c}\boldsymbol{K} \text { after } \\
6 \mathrm{hr} .\end{array}$ \\
\hline $\begin{array}{c}43 \\
45 \\
47 \\
50-75\end{array}$ & $\begin{array}{l}0 \cdot 22 \\
0 \cdot 12 \\
0 \cdot 04 \\
0.00\end{array}$ & $\begin{array}{l}0.22 \\
0.12 \\
0.04 \\
0.00\end{array}$ & $\begin{array}{l}0.23 \\
0.13 \\
0.05 \\
0.00\end{array}$ & $\begin{array}{l}0.22 \\
0 \cdot 14 \\
0.05 \\
0.00\end{array}$ & $\begin{array}{l}0 \cdot 22 \\
0 \cdot 12 \\
0 \cdot 03 \\
0 \cdot 00\end{array}$ & $\begin{array}{l}0 \cdot 21 \\
0 \cdot 11 \\
0 \cdot 03 \\
0 \cdot 00\end{array}$ \\
\hline
\end{tabular}

Conclusions. Ascorbic acid and cysteine do not reduce oxidized bilirubin in alkaline medium. It rather seems that both substances prevent directly the oxidation of bilirubin. In collaboration with R. Roseman', similar observations were made with some polyphenols easily oxidized in alkaline solutions. The experiments are being continued.

Institut de Clinique et de Policlinique Médicales,

G. BARAC Université de Liége. June 17.

${ }^{1}$ Barac, G., Bull. Soc. Chim. Biol., 21, 1163 (1939).

Barac, G., C.R. Soc. Biol., in the press.

ambrechts, A., and Barac, G., Bull. Soc. Chim. Biol., 21, 1171

- Barac, G., and Roseman, R., Bull. Soc. Chim. Biol., in the press.

\section{Colour Receptors of the Human Fovea}

As soon as the results of Granit's micro-electrode experiments on the retinæ of a nimals were published, it was clear that a method was wanted for obtaining similar information with regard to the colour vision of man. This led to the development of the retinal microstimulator, which consists essentially of a microscope used in reverse, so that greatly diminished images of suitable test light-sources are presented to the eyes of the observer.

With apparatus of suitable design, it is possible to test, point by point, the colour vision of a chosen area of the retina. The dimensions I have used are such that each centimetre on the plotting-board of the apparatus corresponds with 'the cone intercentre distance', that is, the distance between the centre of one foveal cone and that of its next-door neighbours. It has been found possible to record the positions of the test light-sources with an accuracy corresponding to one tenth of this distance. A number of experiments have been performed with this technique, but those to be reported here concern the theories of colour vision. As is well known, Thomas Young's trichromatic theory postulated three colour sensations: red, green and blue. Granit on the other hand, found in the retini of several and blue. Granit, on the other hand, found in the retinm of several types of mammals one 'dominator' and seven 'modulators'. The former was a sense-organ which responded to stimulation by light coming from most of the visible spectrum. The latter, on the contrary, were receptors with responses limited to a narrow part of the spectrum only. Granit found 'modulators' with maxima at the following wave4400. Thus, whereas the difference between two neighbouring units was usually two hundred Angströms, in two places the difference was double that amount, hence dividing them into three groups: yelloworange, green and blue-violet.

Granit's conclusion was that each of the hypothetical 'sensations' of Thomas Young consisted of two or more kinds of 'modulator'. It should be pointed out, however, that whereas Granit's work has been performed on animals, Thomas Young's theory was intended to apply only to man. Physiologists are rightly cautious in such a case as this, for what is found with the former may differ widely from what is found with the latter.

The following results have been obtained. When white light from a small metal fllament electric lamp is caused to move slowly over the fovea, as a narrow exploring pencil, in some places it appears red, in other places green, and in still other places blue. When red, it matches in colour a pencil of red light of $6400 \mathrm{~A}$.; when green, it matches a pencil of green $5400 \mathrm{~A}$.; and when blue, it matches blue of $4800 \mathrm{~A}$. The precise position in the fovea of some of these specific points has been determined with reference to the point of fixation, by measuring the distance between the white test-light and the monochromatic light on which the gaze is fixed. Between these foveal a non-specific response which may be either white or yellow.

non-specific response which may be either white or yellow. foveal positions, and as pale orange in others. Sometimes a mome black spot, due to the presence of in others. Sometimes a minute black spot, due to the presence of an unstimulated receptor, is perceived. A monochromatic yellow light of $5800 \mathrm{~A}$. behaves like a white light, in sometimes appearing white (or pale yellow), sometimes red, sometimes green and sometimes orange. A monochromatic green light or even white, as it is moved slowly from place to place over the fovea.

These experiments point to the following conclusions.

(1) Thomas Young's trichromatic theory of colour vision is substantially correct, since the above tests are held to prove the existence of red receptors, green receptors and blue receptors, in the human fovea. 